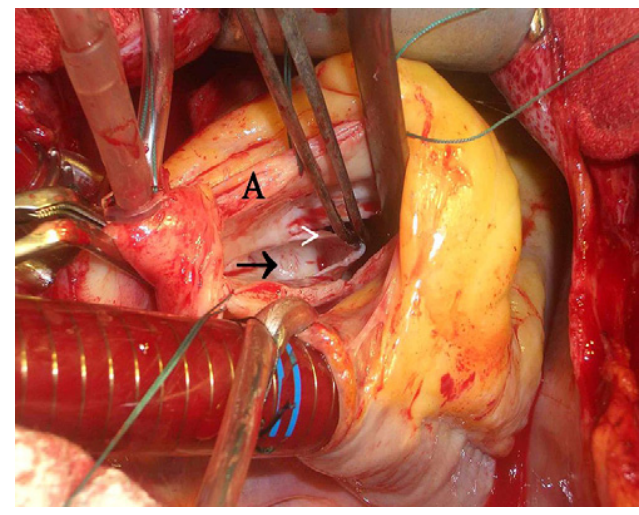

Figure 2. Intraoperative image of left coronary sinus. Total obliteration of left coronary ostium is seen (black arrow). Also note thickened aortic wall (A). White arrowhead indicates left coronary cusp of aortic valve.

patients with TA because of the high rate of subclavian artery occlusion. The long-term graft patency of saphenous vein grafts is reported to be about $60 \%$ at 4 years. $^{3}$

Percutaneous coronary intervention is the choice of revascularization for poor surgical candidates with calcified aortas. Technical and equipment advances have enabled stenting in the unprotected left main coronary artery to be performed with a high initial success rate and acceptable short- to intermediate-term outcomes. Favorable long-term outcomes have also been reported for patients with good left ventricular function, although restenosis occurs in $20 \%$ of patients. ${ }^{2}$ For patients with previously inserted multiple bare metal stents and restenosis, Furukawa and colleagues ${ }^{2}$ used sirolimuseluting stents and observed good 6-month outcomes.

In conclusion, we report a case of TA with obliteration of the left coronary ostium. This was successfully treated with CABG, and the patient was event free at 1 year. CABG, although difficult in some cases of TA, remains the best revascularization option for patients with significant left main trunk stenosis.

We thank Dr Kenneth J. Cherry, University of Virginia, and Sai Jahann for their editing of the manuscript.

\section{References}

1. Liang P, Hoffman GS. Advances in the medical and surgical treatment of Takayasu arteritis. Curr Opin Rheumatol. 2005;17:16-24.

2. Kerr GS, Hallahan CW, Giordano J, Leavitt RY, Fauci AS, Rottem M, et al. Takayasu arteritis. Ann Intern Med. 1994;120:919-29.

3. Ando M, Sasako Y, Okita Y, Tagusari O, Kitamura S, Matsuo H. Surgical considerations of occlusive lesions associated with Takayasu's arteritis. Jpn Heart J. 2000;48:173-9.

\title{
Anomalous left coronary artery from the pulmonary artery with an intramural course within the aortic wall: Report of 3 surgical cases
}

\author{
Steven P. Goldberg, MD, ${ }^{a}$ Max B. Mitchell, MD, ${ }^{a}$ David N. Campbell, MD, ${ }^{a}$ Cecile Tissot, MD, ${ }^{b}$ and \\ Francois Lacour-Gayet, MD, ${ }^{a}$ Denver, Colo
}

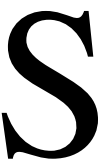

ince 1996, we have operated on 15 patients with anomalous left coronary artery from the pulmonary artery (ALCAPA). Three cases involved a rare variant in which the left coronary artery (LCA) also took an intramural aortic course in the left sinus of Valsalva (LSV) and then exited the aorta to assume its usual pattern.

\footnotetext{
From the Divisions of Cardiothoracic Surgery ${ }^{\mathrm{a}}$ and Pediatric Cardiology, ${ }^{\mathrm{b}}$ The Children's Hospital, Denver, Colo.

Received for publication Sept 27, 2007; accepted for publication Oct 15, 2007.

Address for reprints: Max B. Mitchell, MD, The Children's Hospital, Denver, Division of Cardiothoracic Surgery, 13123 East 16th Avenue, Box B200, Aurora, Colorado 80045 (E-mail: Mitchell.Max@tchden.org).

J Thorac Cardiovasc Surg 2008;135:696-8

$0022-5223 / \$ 34.00$

Copyright $\odot 2008$ by The American Association for Thoracic Surgery doi:10.1016/j.jtcvs.2007.10.033
}

\section{Clinical Summary}

PATIENT 1. A 3-month-old infant underwent an emergency operation for ALCAPA. The LSV was unusually adherent to the adjacent pulmonary artery. The LCA originated from the inferior proximal right pulmonary artery and then took an intramural course in the LSV with normal distal branching. Inside the aorta a "dimple" was observed at the usual site of the LCA origin. A button was transferred to the aorta. Transesophageal echocardiographic analysis demonstrated antegrade LCA flow on cardiopulmonary bypass that was not demonstrable after weaning. The transferred coronary artery was revised by opening the ostium into the distal part of the intramural segment. The opened proximal LCA, adjacent aortic wall, and intima of the unroofed LCA were approximated with interrupted 8-0 Prolene sutures. A left ventricular assist device was required and was weaned at 48 hours. Delayed sternal closure was then achieved. Echocardiographic analysis 6 years after the operation demonstrated a widely patent LCA and normal ventricular function.

PATIENT 2. A 3-year-old patient underwent nonemergency repair of ALCAPA. The LCA originated from the inferior proximal right pulmonary artery. There was dense apposition of the pulmonary artery and adjacent LSV. Probing confirmed an intramural course 


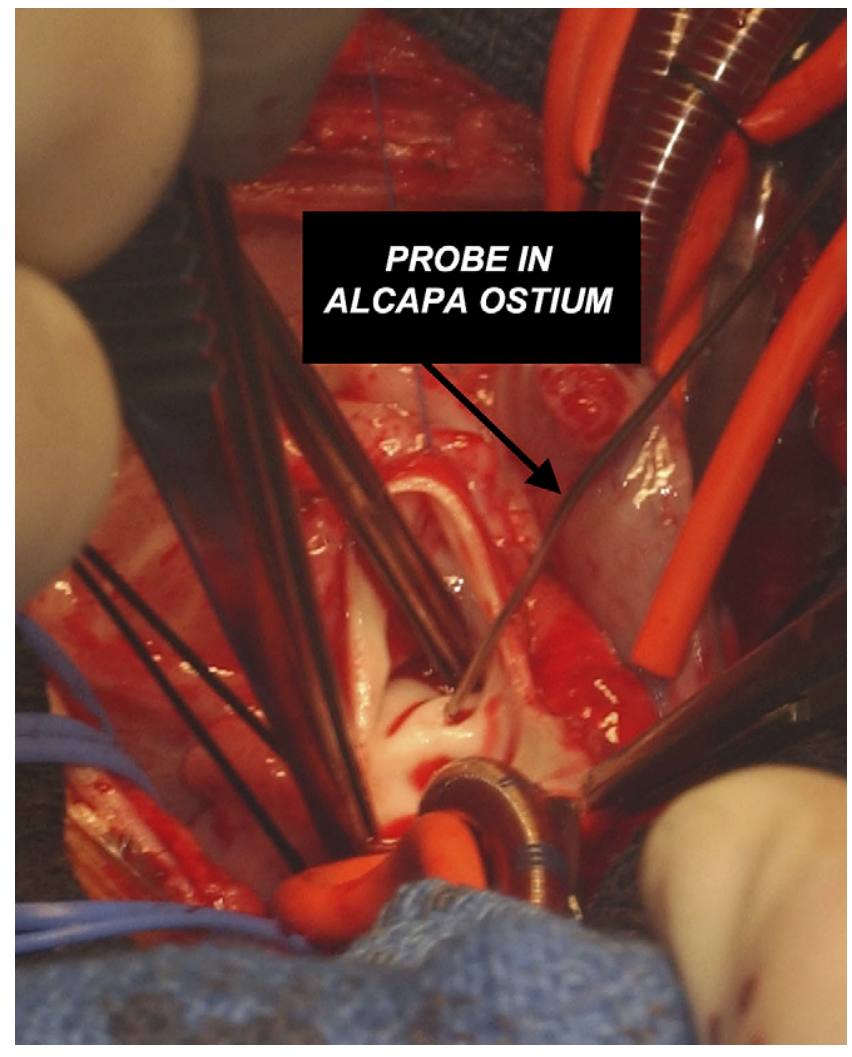

Figure 1. Operative photograph showing the origin of anomalous coronary from the pulmonary artery (photo taken from head of bed).

within the LSV. The LCA was detached from the pulmonary artery and opened into the intramural segment, unroofing it over a coronary probe. An opening was made in the aorta just above the intramural segment. The proximal LCA was connected side to side with 8-0 Prolene sutures, and the unroofed intima was tacked together with interrupted 8-0 Prolene sutures. Catheterization 3 months later demonstrated a widely patent LCA. At 5 years' follow-up, left ventricular function and dimensions are normal.

PAtient 3. A 3-month-old infant was given a diagnosis of restrictive ventricular septal defect, moderate mitral insufficiency, and ALCAPA versus LCA ostial atresia on echocardiographic analysis. At surgical intervention, the LCA was identified in the superior right-facing pulmonary sinus just below the bifurcation (Figure 1). The ostium was unusually small, given the typically large right coronary artery and abundant right-left epicardial collaterals. A $1.5-\mathrm{mm}$ probe was inserted and removed with difficulty. A button was detached, and the LCA trunk was densely adherent to the LSV (Figure 2). Inspection revealed intramural aortic course in the LSV and a linear extraluminal disruption of the LCA in this area. The injury was repaired primarily with 8-0 sutures, the button was transferred to the aorta, and the ventricular septal defect was closed. The patient recovered uneventfully. At 2 months, the patient has no cardiac symptoms. Echocardiographic analysis demonstrated mild mitral regurgitation and normal left ventricular function. By means of Doppler scanning, there is retrograde flow in the proximal left anterior descending artery and antegrade flow in the circumflex artery suggestive of proximal LCA occlusion.

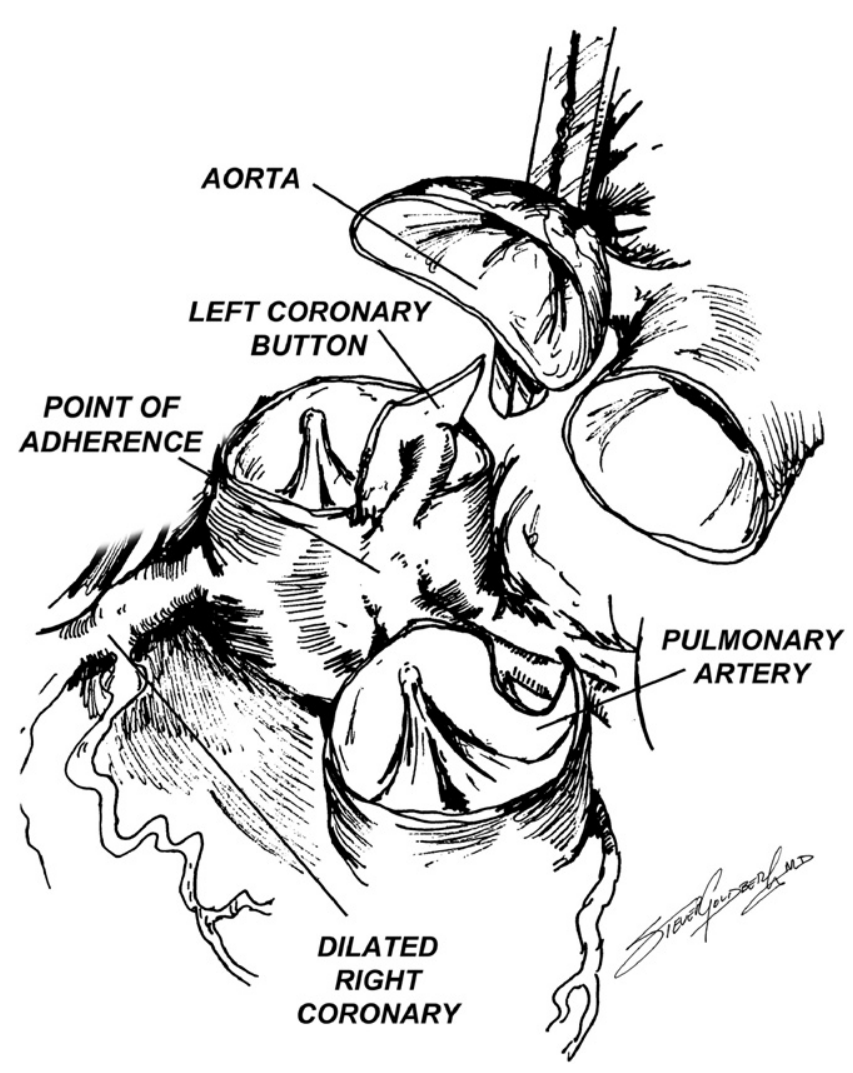

Figure 2. Adherence of anomalous coronary to the aorta, indicating intramural course.

\section{Discussion}

ALCAPA with an intramural aortic course is very rare, and most surgeons are not aware of this anomaly. We find one prior Englishlanguage mention of this entity. ${ }^{1}$ In a series of 11 patients, Turley and colleagues ${ }^{1}$ reported 1 patient with this variant of ALCAPA treated by means of ligation of the LCA at the pulmonary artery and coronary unroofing in the LSV. A Portuguese-language report described 4 similar cases. ${ }^{2}$ Three patients did well with proximal ligation and unroofing of the intramural LCA. One patient underwent LCA button transfer alone and died after a prolonged hospital course.

Our experience and these limited reports indicate that this entity is most commonly discovered intraoperatively. We agree with Atik and associates ${ }^{2}$ that this anatomy should be suspected when the LCA arises at or near the right pulmonary artery origin. A second common finding in our patients was unusual adherence of the LSV to the pulmonary artery, which occurs as a result of the short distance between the LCA origin and the intramural segment. This characteristic places the LCA trunk at risk of injury during initial dissection. In patient 3 the proximal LCA trunk was stenotic from its origin through the intramural segment. Advance recognition of the intramural course might have prevented the described LCA injury. Lastly, coronary transfer alone might kink the intramural portion of the LCA, as observed in patient 1 . We agree with Atik and associates ${ }^{2}$ that unroofing of the intramural portion of the LCA is the preferred method of repair for this unusual variant. 


\section{References}

1. Turley K, Szarnicki RJ, Flachsbart KD, Richter RC, Popper RW, Tarnoff H. Aortic implantation is possible in all cases of anomalous origin of the left coronary artery from the pulmonary artery. Ann Thorac Surg. 1995;60:84-9.
2. Atik E, Barbero-Marcial M, Tanamati C, Kajita L, Ebaid M, Jatene A. Anomalous origin of the left coronary artery from the right pulmonary artery with intramural aortic trajectory: clinicosurgical diagnostic implications [translated from Portguese]. Arq Bras Cardiol. 1999;73: 186-90.

\title{
Retrograde aortic perfusion dislodges a dislodged Amplatzer device
}

\author{
Zubair Luqman, FCPS, Junaid A. Ansari, FRCS(CTh), Hameed Ullah, FCPS, and Mohammad Muneer Amanullah, FRCS(CTh), \\ Karachi, Pakistan
}

$\mathrm{T}$

ranscatheter closure of secundum atrial septal defects (ASDs) with an Amplatzer septal occluder (ASO) (AGA Medical Corporation, Golden Valley, Minn) has become a standard procedure in most pediatric and adult populations. ${ }^{1}$ Different series have reported successful closure of ASDs with good follow-up..$^{1-3}$ One of the most frequently reported complications is device embolization/malposition. ${ }^{1}$ Devices usually embolize into the main pulmonary artery. We report a case of device embolization into the aorta and the strategy for surgical retrieval.

\section{Clinical Summary}

A 53-year-old woman presented to the cardiology clinic with complaints of palpitations. Echocardiographic analysis revealed a 15$\mathrm{mm}$ secundum ASD. She underwent elective closure of the ASD with ASO without any complications. Her predischarge echocardiogram revealed that the ASD was still present. Fluoroscopic study of the thorax showed that the device had embolized into the ascending aorta (Figure 1). She was taken to the operating room for retrieval of the device and closure of the ASD. A transesophageal echocardiogram (TEE) was performed after induction, which confirmed the presence of the device in the ascending aorta just proximal to the innominate artery. The initial plan was to start the patient on circulatory arrest and retrieve the device. Femoral bypass was initiated, and hypothermia was used. Adequate exposure of the ascending aorta was obtained, avoiding manipulation of the aorta, with plans of aortotomy and ASO retrieval during circulatory arrest.

On initiation of femoral bypass, it was observed on TEE that the device could no longer be visualized in the ascending aorta. A fluoroscopic scan using a C-arm was performed, and it demonstrated

From the Division of Congenital Cardiac Surgery, Department of Surgery, the Aga Khan University Hospital, Karachi, Pakistan.

Received for publication Sept 28, 2007; accepted for publication Oct 31, 2007.

Address for reprints: Mohammad Muneer Amanullah, FRCS(CTh), Congenital Cardiac Surgery, the Aga Khan University Hospital, Stadium Road, PO Box 3500, Karachi 74800, Pakistan (E-mail: muneer.amanullah@aku.edu).

J Thorac Cardiovasc Surg 2008;135:698-9

$0022-5223 / \$ 34.00$

Copyright $\odot 2008$ by The American Association for Thoracic Surgery doi:10.1016/j.jtcvs.2007.10.050

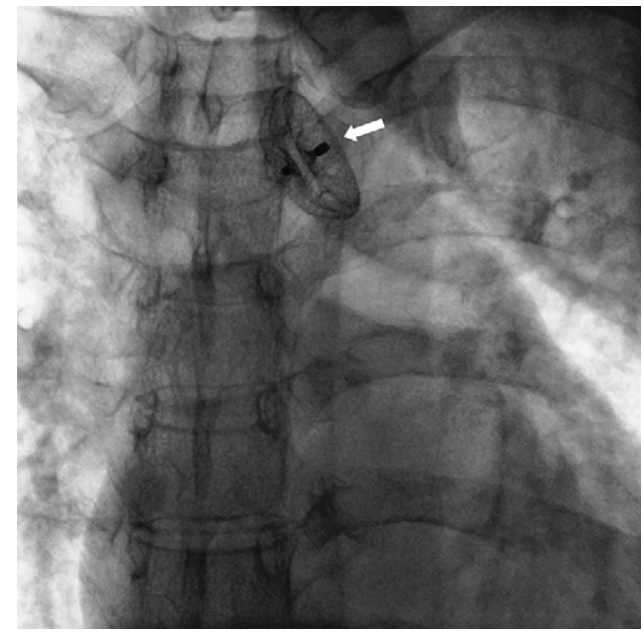

Figure 1. Photograph showing the dislodged amplatzer device in the ascending aorta (white arrow).

that the device had embolized back into the left ventricle. An aortic crossclamp was applied, and antegrade cold blood cardioplegia was administered. A right atriotomy was performed, and the device was visualized through the ASD to be lying in the left ventricle, entangled in the chordae of the mitral valve. The device was retrieved through the ASD. Direct closure of the ASD was performed with Prolene sutures (Ethicon, Inc, Somerville, NJ). The right atriotomy incision was closed. Postoperative echocardiographic analysis did not reveal any residual defect or mitral or aortic valve insufficiency. The patient made a smooth postoperative recovery and was discharged in a week.

\section{Discussion}

ASOs have been used successfully in the adult population, with a low failure rate. ${ }^{1}$ Device embolization or malposition is the most frequently reported complication, and in one series it was $3.5 \%{ }^{2}$

It is reported that there is an age-related decrease in the rate of complications for device closure of ASD, with studies involving children having the lowest complication rates. ${ }^{4}$ Embolization of a device in an adult has rarely been reported. 